\title{
HIV-1 genotypic resistance profile of patients failing antiretroviral therapy in Paraná, Brazil
}

\section{Authors}

Paula Virginia Michelon Toledo, $\mathrm{MD}^{1}$

Denise Siqueira de Carvalho, $\mathrm{PhD}^{1}$

Luiza Romagnoli ${ }^{1}$ Gustavo Marcinko, MD ${ }^{1}$ Clovis Arns da Cunha, $\mathrm{MD}^{1}$

Margely Nunes de Souza Rodrigo Brindeiro, $\mathrm{PhD}^{3}$ Flávio de Queiroz-Telles $\mathrm{PhD}^{1}$

${ }^{1}$ Universidade Federal do Paraná, Curitiba, PR, Brazil.

${ }^{2}$ Centro de Medicamentos do Paraná, Curitiba, PR, Brazil.

${ }^{3}$ Virology Laboratory, National Genotyping Network, Universidade Federal do Rio de Janeiro, RJ, Brazil.
Submitted on: 02/25/2010 Approved on: 06/10/2010

\section{Correspondence to:} Paula Virginia Michelon Toledo

Travessa Amando Mann, 92 sobrado 2

Curitiba - Paraná - Brazil CEP: 80430-010

Phone: +55-41-37796018; 88940327

Phone (Fax):

+55-41-37796018,

e-mail: paulavmtoledo@

yahoo.com.br

We declare no conflict of interest.

\begin{abstract}
Antiretroviral therapy (ART) has reduced morbidity and mortality related to human immunodeficiency virus (HIV) infection, but in spite of this advance, HIV mutations decrease antiretroviral susceptibility, thus contributing to treatment failure in patients. Genotyping HIV-1 allows the selection of new drugs after initial drug failure. This study evaluated the genotypic profile of HIV-1 isolates from treated (drug-experienced) patients in Paraná, Brazil. The prevalence of mutations in reverse transcriptase (RT) and protease (PR) genes were assessed. We analyzed 467 genotypes of patients with HIV-1 viral loads above 1,000 copies/mL. Mutations at HIV-1 RT and PR genes and previously used ART regimens were recorded. The most prevalent RT mutations were: $184 \mathrm{~V}(68.31 \%), 215 \mathrm{YF}$ (51.6\%), 103NS (46\%), 41L (39.4\%), 67N (38.54\%), 210W (23.5\%), 190ASE (23.2\%), and 181C (17.4\%). PR mutations were 90M (33.33\%), 82ATFS (29\%), 46I (26.8\%) and 54V (22.2\%). The prevalence of mutations was in line with previous national and international reports, except to nonnucleoside analogue reverse transcriptase inhibitors related mutations, which were more prevalent in this study. Previous exposure to antiretroviral drugs was associated with genotypic resistance to specific drugs, leading to treatment failure in HIV patients.
\end{abstract}

Keywords: HIV-1, genotype, antiretrovirals, drug-experienced patients.

[Braz J Infect Dis 2010;14(4):360-371] @Elsevier Editora Ltda.

\section{INTRODUCTION}

Since the last decade, antiretroviral therapy (ART) has been altering the course of human immunodeficiency virus (HIV) infection in Brazil, with dramatic decrease in mortality and morbidity. HIV emerged as a potentially treatable chronic infection. ${ }^{1,2}$ In Brazil, in 2008, the estimated number of patients on combination of antiretroviral (ARV) classes, the so-called highly active antiretroviral therapy (HAART), was $185,000 .^{2}$

Some factors, like poor compliance (related to toxicity or complexity of regimens), prescription of suboptimal treatments and the "genetic barrier" of some regimen promote a non-suppressive ART, which strongly contributes to the selection of resistant HIV-1 mutants. ${ }^{3}$ High and continuous replication rate of HIV-1 in vivo, in addition to the error-prone nature of the viral enzymes, in the setting of inadequate levels of ARVs, lead to marked genetic variation with viral mutations that confer drug resistance. ${ }^{4,5}$
Development of drug resistance is one of the most serious obstacles to sustained suppression of HIV and, eventually, multidrug resistance can exhaust the patient's therapeutic options. This population with rising levels of plasma HIV RNA represents potential transmitters of HIV, including drug-resistant strains, to susceptible people. ${ }^{3,6-8}$

Since the first report of zidovudine resistance in clinical isolates from treated patients in 1989,, 10 data on prevalence of resistance have been published in different geographic areas. Genotyping HIV-1 allows for mutations detection in HIV genome, particularly at the protease (PR) and reverse transcriptase (RT) genes. Based on a large knowledge accumulated and published by many authors about PR and RT mutations in the last 10 years, genotype report helps to target selection of new drugs after initial drug failure. ${ }^{11-13}$

Internationally, reports estimating the prevalence of antiretroviral resistance have shown epidemiological features of the global burden of resistance through the years. ${ }^{14-19}$ 
National epidemiological studies have also been reviewed. In 2002, Tanuri et al. published data from a Brazilian database. ${ }^{20}$ From 2004 to 2007, many other authors showed data from the prevalence of antiretroviral resistance in adults from Bahia, São Paulo, Rio de Janeiro, Federal District and North Eastern states. ${ }^{21-27}$

The aim of this study is to analyze the genotypic profile of patients tested for resistance in the Brazilian state of Paraná, in order to determine the frequency of RT and PR mutations among patients failing ART.

\section{MATERIAL AND METHODS}

This study was approved by the Ethics Committee of Hospital de Clínicas of Federal University of Paraná (UFPR) and by the Laboratory Division of Brazilian AIDS Programme (PN-DST/AIDS) of Brazilian Ministry of Health $(\mathrm{MH})$.

\section{Study population and antiretroviral therapy}

Adults on ARV treatment failure in Paraná, Brazil, with genotyping tests from 2002 to 2006 were selected. Genotypes were obtained as part of routine clinical care and indicated when a patient on ART presented virologic failure. The sources were genotypes from private patients and local genotype results from the National Genotyping Network (RENAGENO). An informed consent was signed by all patients before sample collection.

The observational analysis included patients' ART history, viral load (VL) in every ARV regimen failure, CD4 counts (nadir and last available count before genotyping), and PR and RT HIV-1 mutations. Therapeutic failure was defined as VL higher than 1,000 copies $/ \mathrm{mL}$ after continuous use ART for more than three months. Patients whose tests were performed by RENAGENO had VL higher than 5,000 copies $/ \mathrm{mL}$.

Patients should have been exposed to at least two ARV, including: nucleoside analogue reverse transcriptase inhibitors (NRTIs), non-nucleoside analogue reverse transcriptase inhibitors (NNRTIs), and protease inhibitors (PIs). Patients were excluded when information about ART was missing or incomplete.

HAART was defined as a combination of at least three antiretroviral agents, including two NRTIs and a NNRTI or a PI. Some patients used boosted PIs. NRTI mono or double therapy were considered non-HAART regimen.

\section{Genotypes description}

Genotypings were done by polymerase chain reaction (PCR) amplification and DNA sequencing technique. The HIV-1 genomic region analyzed was POL, specifically the PR and RT codons. Genotypic sequencing was performed using commercially available assays, with over $70 \%$ of samples being tested with ViroSeq HIV-1 Genotype System ${ }^{\circledR}$.
Reports from RENAGENO where performed by ViroSeq HIV-1 Genotype System ${ }^{\circledR}$ from Celera Diagnostics (Applied Biosystems). Reports of private patients were performed by one of the following assays: GenoSure ${ }^{\circledR}$ (by LabCorp), vircoTYPE HIV-1 ${ }^{\circledR}$ (by VIRCO) and GeneSeq ${ }^{\circledR}$ (by Monogram, formerly ViroLogic Inc.).

The epidemiology of mutations found was described and no Genotype Algorithm was used to interpret results in this study.

\section{Mutations definition}

Mutations associated with reduced antiretroviral drug susceptibility are described below and were based on the compilation of data reported by the Stanford University HIV Drug Resistance Database, updated in 2005 and 2008, ${ }^{11,28}$ and the International AIDS Society - USA Panel Guidelines reports from 2000 to 2008. ${ }^{12,29-41}$

Mutations associated with reduced susceptibility to NRTIs are at RT gene positions 41, 43, 44, 62, 65, 67, $69,70,74,75,77,115,116,118,151,184,208,210,215$, $218,219,221$, and 228. Thymidine associated mutations (TAMs) are M41L, D67N, K70R, L210W, T215YF, K219QE. Accessory mutations include K43EQ, E44AD, V118I, H208Y, D218E, H221Y, and L228HR. The nonthymidine associated mutations are K65R, K70EG, L74V, Y115F, M184VI. Additional mutations are related to treatment with NRTI with no clear phenotypic significance, and include D67GE, T69DSAN, V75AS, K219NR. Multi-NRTI resistance mutations that confer resistance to all NRTIs are 69 insertion, A62V, V75I, F77L, F116Y, Q151M.

NNRTIs-associated mutations included amino acid substitutions at RT gene positions A98G, L100I, K101E/P, K103N/S, V106A/M/I, V108I, V179D/E/F/T, Y181C/I/V, Y188C/H/L, G190A/S, P225H, F227L/C, M230L, and K238T.

Major PI mutations included amino acid substitutions at PR gene positions D30N, V32I, L33F, M46I/L, I47V/A, G48V/M, I50L/V, I54M/L, Q58E, T74P, V82A/ F/L/T/S, I84V/A/C, N88D/S, and L90M. Minor PI mutations included the substitutions in positions $\mathrm{L} 10 \mathrm{~F} / \mathrm{I} / \mathrm{R} / \mathrm{V}$, V11I, I13V, G16E, K20M/R/I/T, L23I, L24I, E34Q, E35G, M36I/V, K43T, F53L, I54V/T/A/S, D60E, I62V, L63P, $\mathrm{I} 64 \mathrm{~L} / \mathrm{M} / \mathrm{V}, \mathrm{A} 71 \mathrm{~V} / \mathrm{T} / \mathrm{I}, \mathrm{G} 73 \mathrm{~S} / \mathrm{T}, \mathrm{L} 76 \mathrm{~V}, \mathrm{~V} 77 \mathrm{I}, \mathrm{N} 83 \mathrm{D}, \mathrm{I} 85 \mathrm{~V}$, $\mathrm{L} 89 \mathrm{~V}$, and $\mathrm{I} 93 \mathrm{~L} / \mathrm{M}$ of PR.

\section{Database construction}

Collection Data was stored at Access 2007 for Windows Vista and exported to Excel 2007 for Windows Vista for analyses. There were 393 variables, including every TR and PR mutations, data about previous ART, and demographic data. 


\section{Statistical analysis}

Statistical analyses were performed with STATA 8.2 for Windows (Statacorp, Texas).

The distribution of categorical variables was compared using the Chi square-test. Odds ratio was used to compare differences in frequencies. We studied the association between mutations and sex, as well as changes of mutations prevalence throughout the years.

The association between the presence of mutation and previous exposure to certain ARV was assessed by univariate and multivariate analyses. Dependent variables were the mutations, and the ARV exposure was the independent variable.

The significance level of 0.05 and a Confidence Interval (CI) of $95 \%$ were used.

\section{RESULTS}

From more than 600 genotypes performed from 2002 to 2006, 467 genotypes of 467 patients from Paraná State were evaluated. The genotypes of paediatric patients and the exams of patients whose ART history could not be elucidated were excluded. For patients with more than one genotype, the most recent one was included. RENAGENO performed $73.7 \%$ of the genotypes (Table 1 ). PR and RT subtype was defined in 389 (83.3\%) patients,

Table 1. Characterization of the study genotypes by date of collection and methodology of performance

\begin{tabular}{|lcc|}
\hline & Number (n) & Frequency (\%) \\
\hline Date of genotype & & \\
\hline 2002 & 22 & 4.71 \\
\hline 2003 & 30 & 6.42 \\
\hline 2004 & 117 & 25.05 \\
\hline 2005 & 186 & 39.83 \\
\hline 2006 & 112 & 23.98 \\
\hline Genotype assay & & \\
\hline $\begin{array}{l}\text { ViroSeq System } \\
\text { Applied biosystems } \\
\text { (Renageno) }\end{array}$ & 344 & 73.66 \\
\hline $\begin{array}{l}\text { VircoTYPE HIV-1 } \\
\text { (VIRCO) }\end{array}$ & 83 & 17.77 \\
\hline $\begin{array}{l}\text { GenoSure } \\
{ }^{\circledR} \text { (LabCorp) }\end{array}$ & 22 & 4.71 \\
\hline $\begin{array}{l}\text { GeneSeq } \\
\text { (Monogram, ViroLogic) }\end{array}$ & 18 & 3.85 \\
\hline
\end{tabular}

$\mathrm{PR}=$ protease, $\mathrm{RT}=$ reverse transcriptase . most of them (61.4\%) were subtype B, 20.6\% subtype C and $4.9 \%$ were subtype F. About $13.1 \%$ of the patients showed mixtures in PR and RT subtypes.

Mean age of patients in study was $41.12 \pm 9.1$ years, and most of them $(n=308 ; 66 \%)$ were males. Mean viral load in patients with failing regimens - including NRTI, NNRTI, and PI - was of 1,000 to 30,000 copies/mL. Most patients (72\%) had AIDS and 56.7\% had mean nadir CD4 count lower than 150 cells/mL. After ART, 59.6\% had CD4 count above 200 and $31 \%$ above 350 cells $/ \mathrm{mL}$, in spite of virologic failure.

Patients were exposed to $6.69 \pm 2.94 \mathrm{ARV}$ s and $4.03 \pm$ 2.45 ART combinations. The three ARV classes (NRTI, NNRTI, and PI) were used by $296(63.4 \%)$ patients. Seventy three (15.6\%), $89(19.1 \%)$ and $9(1.9 \%)$ patients used PI plus NRTI, NNRTI plus NRTI and NRTI double therapy, respectively.

NRTI double therapy was the most frequent initial regimen (Table 2). From patients starting on two NRTI, 59.16\% received a PI containing HAART and $36.12 \%$ received a NNRTI containing HAART as subsequent therapy.

HAART used when genotype was requested included lamivudine in $80.94 \%$, a NNRTI in $50.54 \%$ and a boosted PI in $35.55 \%$ (Figure 1).

Mean duration of drug exposure was longer for NRTIs and shorter for some PIs, like saquinavir (Table 3).

Table 2. Patterns of initial and last antiretroviral regimen used

\begin{tabular}{|lcc|}
\hline & Number (n) & Frequency (\%) \\
\hline Initial regimen & 179 & 38.33 \\
\hline \multicolumn{1}{|c|}{ NRTI + PI } & 6 & 1.28 \\
\hline \multicolumn{1}{|c|}{ NRTI + boosted PI } & 65 & 13.92 \\
\hline \multicolumn{1}{|c|}{ NRTI + NNRTI } & 27 & 5.78 \\
\hline \multicolumn{1}{|c|}{ Monotherapy (AZT) } & 191 & 40.89 \\
\hline \multicolumn{1}{|c|}{ NRTI double therapy } & & \\
\hline Last regimen & 95 & 20.34 \\
\hline NRTI + PI & 166 & 35.55 \\
\hline NRTI + boosted PI & 236 & 50.54 \\
\hline NRTI + NNRTI & 0 & 0 \\
\hline Monotherapy (AZT) & 9 & 1.93 \\
\hline NRTI double therapy &
\end{tabular}

NRTI = nucleoside analogue reverse transcriptase inhibitors, NNRTI = non-nucleoside analogue reverse transcriptase inhibitors, PI = protease inhibitors, AZT = zidovudine. 
The wild-type virus was present in 23 (4.9\%) patients. Mutations conferring resistance to only one ARV class were seen in 66 (14.1\%) patients. Resistance-mutations to two ARV classes were detected in 241 (51.6\%) patients, and most of them were resistant to NRTI and NNRTI (59.34\%), followed by resistance to NRTI and PI (38.6\%), and to PI and NNRTI (2.1\%). Resistance mutations to the three classes was detected in 137 (29.3\%) patients.

Any NRTI mutation was present in 405 (86.7\%) patients. M184V alone was detected in $64(13.7 \%)$ patients. The prevalence of NRTI-related mutations is showed in Figures 2 and 3. Most patients ( $88 \%$ ) were on thymidine analogues at the time of genotype and $99.8 \%$ of patients were previously exposed to a thymidine NRTI, $45 \%$ had more than three TAMs, and $21.8 \%$ had both M41L and L210W mutations, but 32.8\% had no TAMs.

NNRTI-related mutations were present in 316 (67.7\%) patients and the most frequent were K103NS, G190AES, and Y181C. The prevalence of NNRTI-related mutations present in the group of NNRTI-exposed patients is listed in Figure 4. Three out of 73 (4.10\%) patients exposed only to PI and NRTI presented NNRTI-related mutations: one had K103N mutation, the other patient had Y181C and G190A mutations, and the third one presented Y181C, K101E and A98G mutations.

Major PI mutations were present in 239 (51.2\%) patients and minor PI mutations were present in 455 (97.4\%). The

Figure 1: Overall antiretroviral regimen use (\%) - The dark grey columns represent the frequency of patients on each $\mathrm{ARV}$ at the time of genotype. The light grey columns represent the frequency of patients ever exposed to each ARV since the beginning of treatment.

Nucleoside analogue reverse transcriptase inhibitors: AZT Zidovudine, d4T - Stavudine, 3TC - Lamivudine, ddI - Didanosine, ddC - Zalcitabine, ABC - Abacavir, TDF - Tenofovir.

Non-nucleoside analogue reverse transcriptase inhibitors: EFV Efavirenz, NVP - Nevirapine, DLV - Delavirdine.

Protease Inhibitors: RTV - Ritonavir, SQV - Saquinavir, IDV Indinavir, NFV - Nefinavir, ATV - Atazanavir, APV - Amprenavir, $\mathrm{SQV} / \mathrm{r}$ - Saquinavir/ritonavir, Indinavir/ritonavir (IDV/r), ATV/r - Atazanavir/ritonavir, APV/r - Amprenavir/ritonavir, LPV/r Lopinavir/ritonavir, DRV/r - Darunavir/ritonavir.

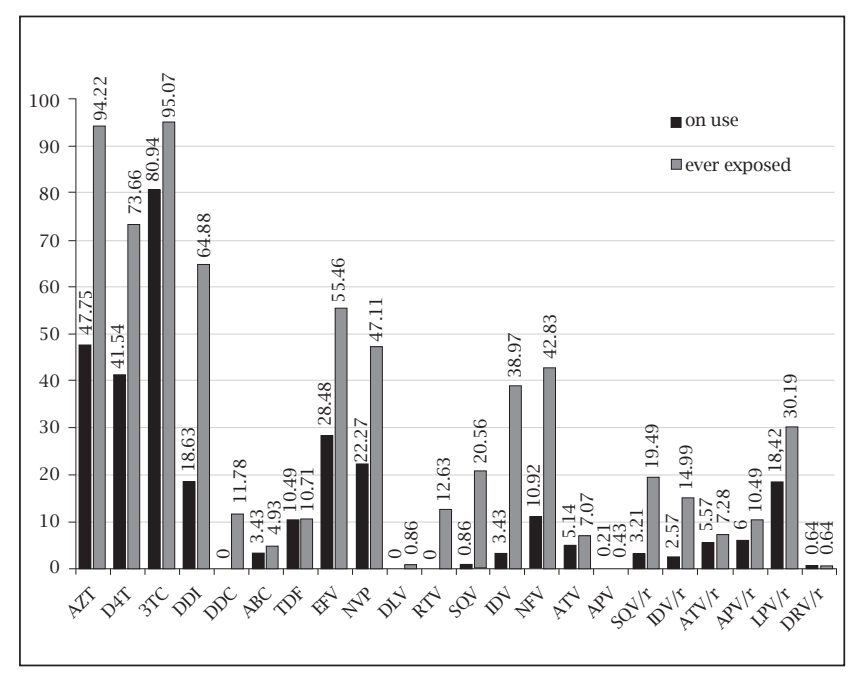

most frequent major PI mutation was L90M. The prevalence of PI-related mutations in the group of patients exposed to PI is listed in Figures 5 and 6. Two out of 89 patients (2.3\%) exposed only to NNRTI e NRTI had major PI-related mutations: one had $30 \mathrm{~N}$ mutation and the other patient had D30N, N88D and L90M mutations.

Exposure to each ARV class was significantly related to the presence of resistance mutations conferring resistance to these classes. NNRTI-related mutations occurred more often after NNRTI exposure (OR 10.57, 95\% CI $=4.03-22.73$, $\mathrm{p}=0.000)$. Likewise, major PI mutations were more frequent after PI exposure (OR 4.55, 95\% CI $=2.45-8.46, \mathrm{p}=0.000)$. Initial therapy consisting of two NRTIs (double therapy) was significantly related to a higher frequency of TAMs (OR 1.69, $95 \% \mathrm{CI}=1.12-2.54, \mathrm{p}=0.01)$ and the higher number of TAMs was also more prevalent in the group of patients who was exposed to double therapy (OR 1.16, 95\% CI $=1.05-1.28, \mathrm{p}=$ 0.004). NNRTI based HAART as first therapy was associated to lower prevalence of TAMs (OR $0.41,95 \% \mathrm{CI}=0.24-0.71$, $\mathrm{p}=0.0009)$.

M184IV was related to lamivudine exposure (OR 26.21, $95 \% \mathrm{CI}=5.66-121.42, \mathrm{p}=0.0000)$. After multivariate analysis, TAMs were associated to longer exposure to $\mathrm{d} 4 \mathrm{~T}$, and patients exposed to ddI and TDF showed significantly more

Table 3. Mean duration of each antiretroviral exposure

\begin{tabular}{|lc|}
\hline Antiretroviral & $\begin{array}{c}\text { Mean duration of exposure } \\
\text { (months) }\end{array}$ \\
\hline Zidovudine & 26 \\
\hline Stavudine & 23 \\
\hline Lamivudine & 40 \\
\hline Didanosine & 8.5 \\
\hline Zalcitabine & 11 \\
\hline Abacavir & 6 \\
\hline Tenofovir & 9 \\
\hline Efavirenz & 10.5 \\
\hline Nevirapine & 10 \\
\hline Delavirdine & 3 \\
\hline Ritonavir & 8 \\
\hline Saquinavir & 2 \\
\hline Indinavir & 11 \\
\hline Nelfinavir & 11 \\
\hline Atazanavir & 10 \\
\hline Amprenavir & 6 \\
\hline Saquinavir/ritonavir & 8.5 \\
\hline Indinavir/ritonavir & 8 \\
\hline Atazanavir/ritonavir & 7 \\
\hline Amprenavir/ritonavir & 9 \\
\hline Lopinavir/ritonavir & 3 \\
\hline Darunavir/ritonavir & 10.5 \\
\hline
\end{tabular}


Figure 2: Prevalence (\%) of NRTI-related mutations I - The horizontal columns represent the frequency of NRTI-related mutations (Thymidine analogue mutations, Accessory and Additional mutations) in the 467 patients evaluated. Each column is described at the legend on the right. Additional mutations are 67G, 69DAN and 75A. Accessory mutations are 43EQ, 44AD, 181I, 208Y, 218E, 221Y and 228H. TAMs are $41 \mathrm{~L}, 67 \mathrm{~N}, 210 \mathrm{~W}, 215 \mathrm{FY}$ and 219EQ. There were no 67E, 69S, $75 \mathrm{~S}$ and $228 \mathrm{H}$ mutations in these patients.

TAMs $=$ thymidine analogue mutations, NRTI = nucleoside analogue reverse transcriptase inhibitors.

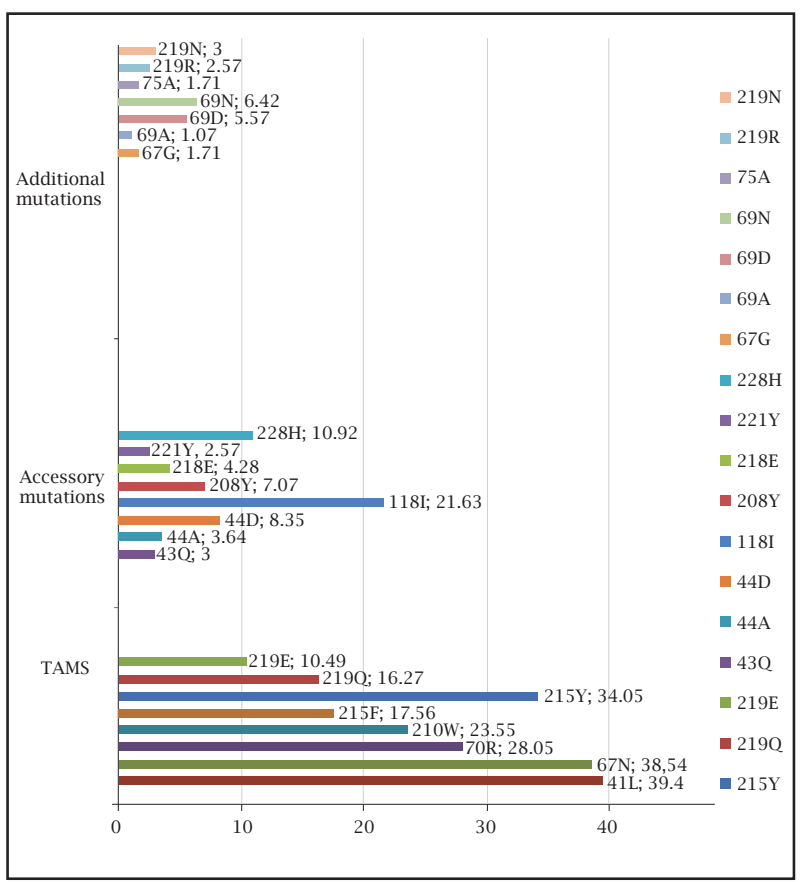

Figure 3: Prevalence (\%) of NRTI-related mutations II - The horizontal columns represent the frequency of NRTI-related mutations (non-thymidine analogue mutations, and multinrti resistance mutations) in the 467 patients evaluated. Each column is described at the legend on the right. NonTAMs are 115F, 75M, 75T, 74I, 74V, 65R e 184V. Multi-NRTI Resistance Mutations are 62V, 75I, 77L, 116Y and 151M and the insertion 69.

TAMs $=$ thymidine analogue mutations, NRTI $=$ nucleoside analogue reverse transcriptase inhibitors.

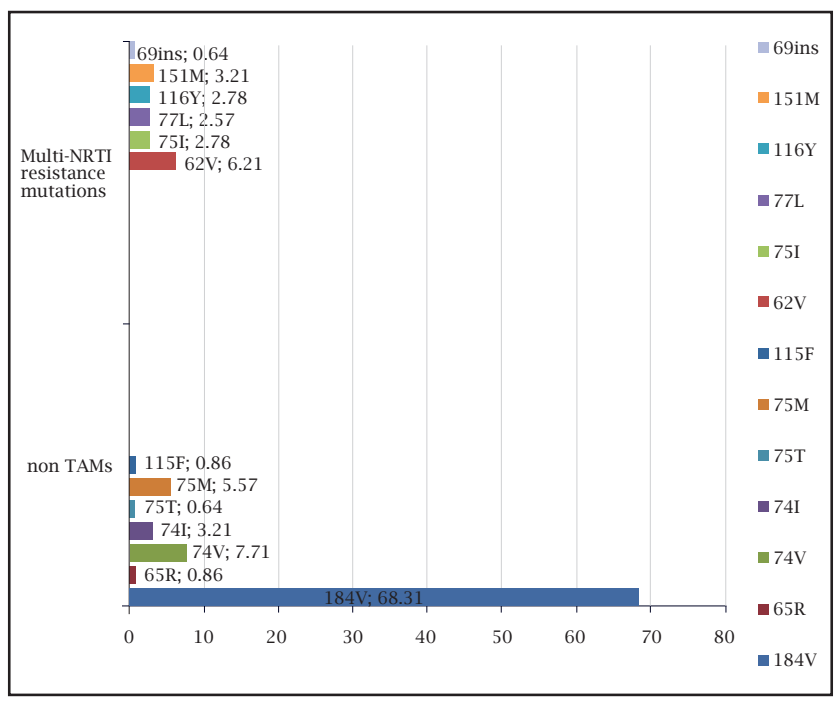

Figure 4: Prevalence (\%) of NNRTI-related mutations - The vertical columns represent the frequency of NNRTI-related mutations in the 382 patients exposed to NNRTIs. Each column is described at the legend on the right. The mutations 179T, 181IV and $188 \mathrm{H}$ were not present in these patients.

NNRTI = non-nucleoside analogue reverse transcriptase inhibitors.

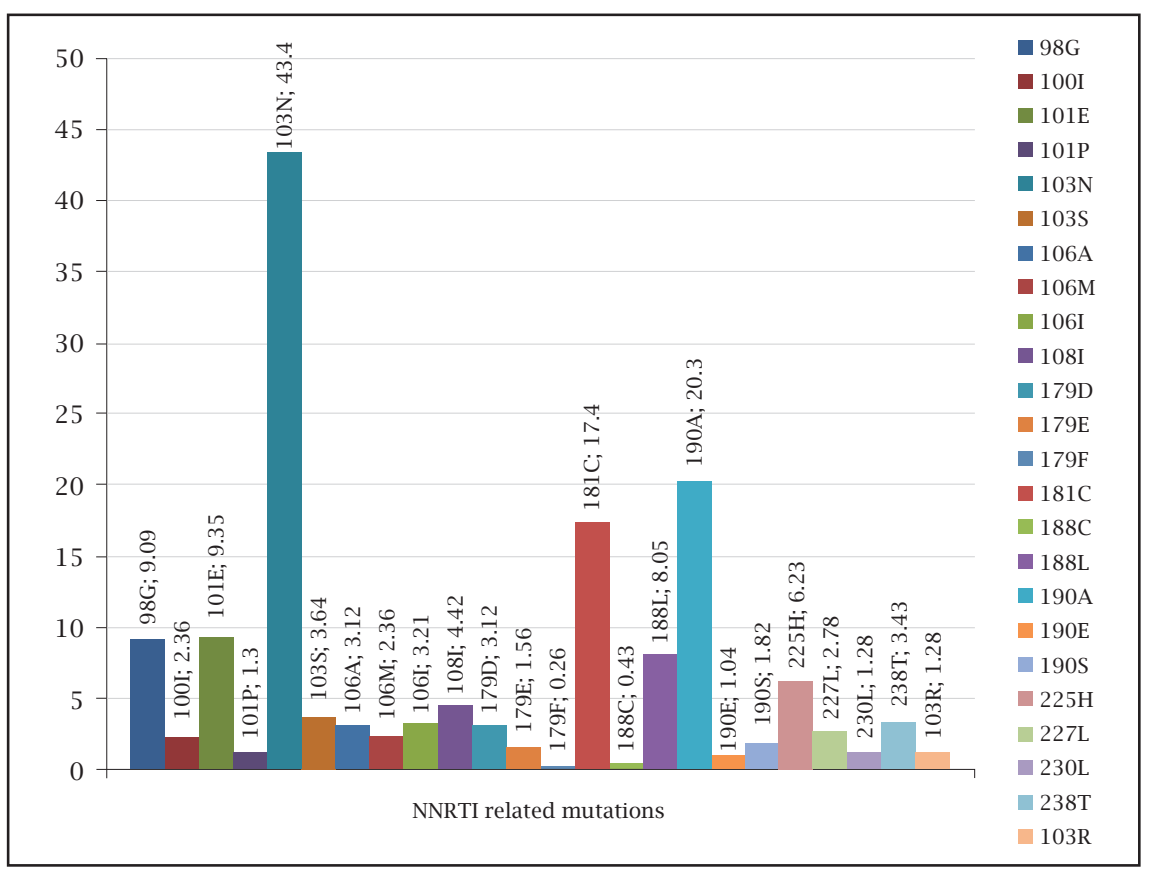


Figure 5: Prevalence (\%) of Major PI-related mutations The vertical columns represent the frequency of PI-related mutations in the 366 patients exposed to PIs. Each column is described at the legend on the right $(30 \mathrm{~N}, 32 \mathrm{I}, 33 \mathrm{~F}, 46 \mathrm{IL}$, 47AV, 48VM, 50LV, 54ML, 58E, 74P, 76V, 82ATFS, 84V, $88 \mathrm{DS}, 90 \mathrm{M})$. The mutations $84 \mathrm{AC}$ were not present in these patients.

$\mathrm{PI}=$ protease inhibitor.

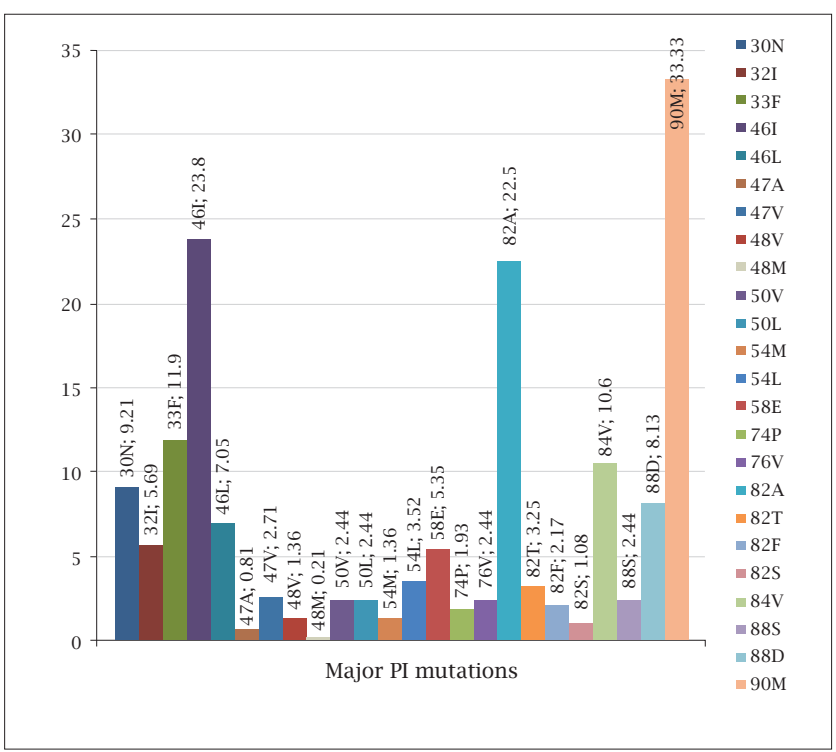

TAMs. Mutations on codons 74, 75 and 115 of RT were associated to longer exposure to TDF and ddI. On multivariate analysis tenofovir exposure was significantly associated to the presence of 74IV (OR 2.67, 95\% CI $=1.27-5.63, \mathrm{p}=$ $0.010)$ and $115 \mathrm{~F}(\mathrm{OR} 1.97,95 \% \mathrm{CI}=1.01-53.60, \mathrm{p}=0.048)$ (Table 4). Likewise, the presence of mutations on codons 103, 101 and 106 was associated to exposure to EFV and NVP. Mutations on codons 181, 190 and 227 were significantly associated to NVP exposure, and at codons 100, 108, 179 and 225, to EFV exposure (Table 5).

Exposure to full dose ritonavir was related to the presence of 33F, 46IL, 47AV, 48V, 50V, 58E, 76V, 82ATFS, 84V, 90M. Exposure to indinavir was related to $32 \mathrm{I}, 33 \mathrm{~F}, 46 \mathrm{IL}, 58 \mathrm{E}, 74 \mathrm{P}, 76 \mathrm{~V}$, 82ATFS, $84 \mathrm{~V}$, 90M. Exposure to boosted indinavir was related to $33 \mathrm{~F}, 46 \mathrm{IL}, 58 \mathrm{E}, 54 \mathrm{ML}, 82 \mathrm{ATFS}, 90 \mathrm{M}$. Exposure to saquinavir was related to 32I, 33F, 48V, 76V, 82ATFS, 84V, 90M. Exposure to boosted saquinavir was related to $33 \mathrm{~F}, 46 \mathrm{IL}, 48 \mathrm{~V}$, 58E, $82 \mathrm{ATFS}, 84 \mathrm{~V}, 90 \mathrm{M}$. Exposure to nelfinavir was related to $30 \mathrm{~N}, 33 \mathrm{~F}, 46 \mathrm{IL}, 50 \mathrm{~L}, 58 \mathrm{E}, 88 \mathrm{DS}$, 90M. Exposure to atazanavir was related to $50 \mathrm{~L}, 74 \mathrm{P}$, and, to boosted atanavir, to $32 \mathrm{I}$, 33F, 46IL, 47AV, 54ML, 82ATFS, 90M. Exposure to boosted lopinavir was related to $46 \mathrm{IL}, 47 \mathrm{AV}, 48 \mathrm{VM}, 50 \mathrm{~V}, 54 \mathrm{ML}, 58 \mathrm{E}$, 76V, 82ATFS, 84V, 90M. Exposure to amprenavir was related to $32 \mathrm{I}, 54 \mathrm{ML}, 58 \mathrm{E}$, and, to boosted amprenavir, to $33 \mathrm{~F}, 46 \mathrm{IL}$, 47AV, 50V, 54ML, 58E, 82ATFS, 84V, 90M. Exposure to boosted darunavir was related to $32 \mathrm{I}, 33 \mathrm{~F}, 47 \mathrm{AV}, 50 \mathrm{~V}, 54 \mathrm{ML}, 76 \mathrm{~V}$.
Figure 6: Prevalence (\%) of Minor PI-related mutations The vertical columns represent the frequency of PI-related mutations in the 366 patients exposed to PIs. Each column is described at the legend on the right (10FIRV, 11I, 13V, 20MIR, 23I, 24I, 34Q, 36IV, 43T, 53L, 54VTAS, 60E, 62V, 63P, 71VIT, 73ST, 77I, 83D, 85V, 89V, 93L). The mutations 16E, 20T, 35G e 64LMV were not present in these patients.

$\mathrm{PI}=$ protease inhibitor.

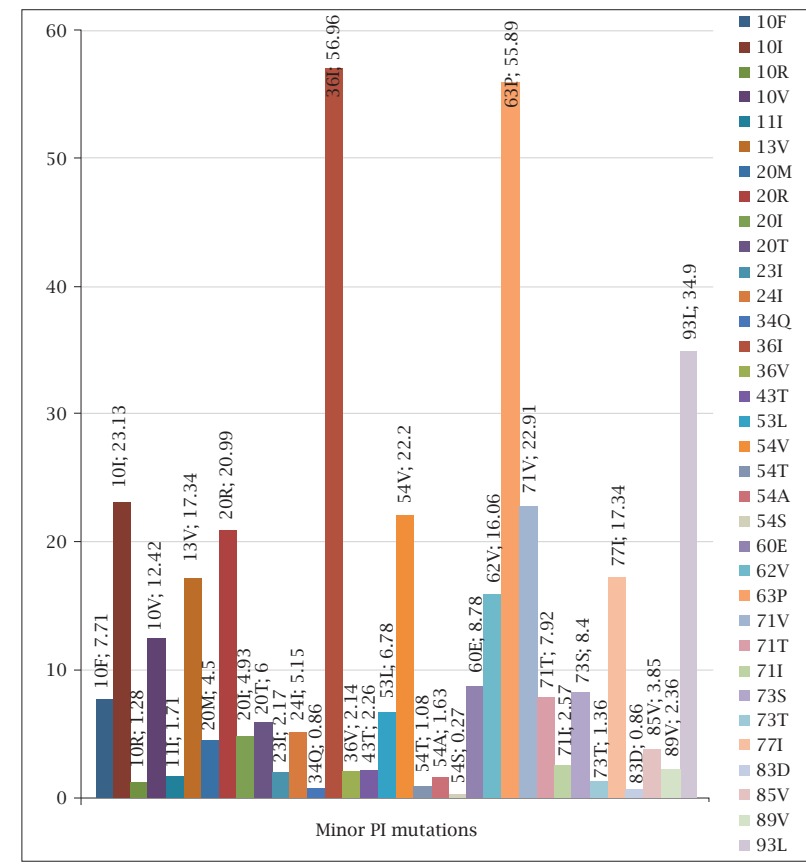

After logistic regression analysis, lopinavir/ritonavir exposure was not a risk factor to the presence of G48VM after controlling for SQV and SQV/r exposure (OR 8.67, 95\% CI = $0.85-87.98, \mathrm{p}=0.068)$. SQV exposure was not associated with the presence of L76V after controlling for DRV/r and LPV/r exposure (OR 3.02, 95\% CI $=0.68-13.67, \mathrm{p}=0.146)$. The presence of 33I was associated only with the exposure to LPV/r, IDV and IDV/R, but not with NFV (OR 1.55, 95\% CI =0.75-3.18, p $=0.234)$ or DRV/r $(\mathrm{OR} 4.74,95 \% \mathrm{CI}=0.40-56.94, \mathrm{p}=0.320)$.

The presence of major PI mutations, TAMs and other NRTI-related mutations was significantly associated with the exposure to a higher number of HAART regimens and a higher number of ARVs (Table 6).

When the frequency of ARV classes' exposure was analyzed, the use of NNRTIs, PIs and exposure to the three ARV classes was similar for patients who were genotyped from 2002 to 2006. There was a significant increase of tenofovir use and 3TC at the moment of test, and an overall decrease of exposure to thymidine analogues from 2002 to 2006 (Table 6).

Overall distribution of resistance mutations related to the three classes had no significant difference throughout the years, except for the significantly higher prevalence of accessory mutations (Figures 7 and 8). Some isolated mutations became significantly more prevalent over time (Table 7).

Some TAMs, V118I and PI mutations, like L90M, were more frequent in the HIV-1 isolates of male patients (Table 8). 
Table 4. Multivariate analyses to NRTI exposure and presence of TAMs

\begin{tabular}{lllcc}
\hline Mutation & ARV exposure & OR* & 95\% IC & p-value \\
\hline TAMs & Exposure to AZT & 0.99 & $0.44-2.28$ & 0.999 \\
& Longer AZT exposure & 1.16 & $1.00-1.34$ & 0.051 \\
& Exposure to d4T & 1.02 & $0.65-1.61$ & 0.926 \\
& Longer d4T exposure & 1.25 & $1.09-1.43$ & 0.001 \\
& Exposure to TDF & 3.36 & $1.39-8.15$ & 0.003 \\
& Exposure to ddI & 1.85 & $1.23-2.78$ & 0.007 \\
\hline $74 \mathrm{IV}$ & Longer ddI exposure & 1.42 & $1.12-1.78$ & 0.0031 \\
& Longer TDF exposure & 2.71 & $1.54-4.77$ & 0.0005 \\
\hline $75 \mathrm{TM}$ & Longer ddI exposure & 1.42 & $1.05-1.90$ & 0.0214 \\
& Longer TDF exposure & 2.73 & $1.33-5.62$ & 0.0064 \\
\hline \multirow{2}{*}{$115 \mathrm{~F}$} & Longer ddI exposure & 2.64 & $1.36-59.89$ & 0.0141 \\
& Longer TDF exposure & 9.04 & & 0.0225 \\
\hline
\end{tabular}

TAMs = thymidine analogue mutations, NRTI = nucleoside analogue reverse transcriptase inhibitors, AZT $=$ zidovudine, $\mathrm{d} 4 \mathrm{~T}=$ stavudine, $\mathrm{TDF}=$ tenofovir, $\mathrm{ddI}=$ didanosine .

$\mathrm{OR}=$ odds ratio, $\mathrm{CI}=$ confidence interval.

*Odds ratio for the occurrence or not of mutations when patients were exposed to these ARVs..

Table 5. Multivariate analyses to NNRTI exposure and presence of NNRTI related mutations

\begin{tabular}{|c|c|c|c|c|}
\hline Mutation & ARV exposure & $\mathrm{OR}^{*}$ & $95 \%$ IC & p-value \\
\hline 100I & \multirow{4}{*}{ Exposure to EFV } & 12.05 & $2.50-58.17$ & 0.0001 \\
\hline $108 \mathrm{I}$ & & 2.11 & $1.00-4.53$ & 0.0484 \\
\hline 179DEF & & 9.18 & 1.16-72.92 & 0.0107 \\
\hline $225 \mathrm{H}$ & & 10.97 & $3.86-31.19$ & 0.0000 \\
\hline $181 C$ & \multirow{3}{*}{ Exposure to NVP } & 9.92 & $4.58-21.49$ & 0.0000 \\
\hline 190ASE & & 4.26 & $2.50-7.29$ & 0.0000 \\
\hline 227L & & 3.87 & $1.04-14.37$ & 0.0291 \\
\hline \multirow[t]{2}{*}{$101 \mathrm{EPH}$} & \multirow{6}{*}{ Exposure to EFV and NVP } & 2.04 & $1.02-4.06$ & 0.0383 \\
\hline & & 2.30 & $1.13-4.67$ & 0.0178 \\
\hline \multirow[t]{2}{*}{$103 N S$} & & 3.92 & 2.52-6.09 & 0.0000 \\
\hline & & 4.28 & $1.17-15.70$ & 0.0168 \\
\hline \multirow[t]{2}{*}{ 106AM } & & 8.31 & $1.04-66.47$ & 0.0168 \\
\hline & & 3.46 & $1.47-8.17$ & 0.0025 \\
\hline
\end{tabular}

NNRTI = non-nucleoside analogue reverse transcriptase inhibitors, EFV = efavirenz, NVP = nevirapine.

$\mathrm{OR}=$ odds ratio, $\mathrm{CI}=$ confidence interval.

*Odds ratio for the occurrence or not of mutations when patients were exposed to these ARVs. 
Table 6. Amount of ARV exposure and presence of mutations

\begin{tabular}{|c|c|c|c|c|}
\hline Mutation & ARVs and regimens & $\mathrm{OR}^{*}$ & 95\% CI & p-value \\
\hline TAMs & Increasing number of HAART regimen & 1.11 & $1.03-1.20$ & 0.0082 \\
\hline TAMs-Accessory mutations & & 1.11 & $1.02-1.20$ & 0.0094 \\
\hline Multi-NRTI resistance mutations & & 1.15 & $1.02-1.30$ & 0.0247 \\
\hline NNRTI mutations & & 1.09 & $1.01-1.18$ & 0.0301 \\
\hline Major PI mutations & & 1.28 & $1.19-1.37$ & 0.0000 \\
\hline TAMs & Increasing number of ARV exposure & 1.08 & $1.01-1.15$ & 0.0214 \\
\hline TAMs-Accessory mutations & & 1.10 & $1.02-1.17$ & 0.0056 \\
\hline NRTI-Additional mutations & & 1.14 & $1.05-1.24$ & 0.0017 \\
\hline Multi-NRTI resistance mutations & & 1.13 & $1.02-1.25$ & 0.0208 \\
\hline Major PI mutations & & 1.26 & $1.18-1.34$ & 0.0000 \\
\hline
\end{tabular}

ARV = antiretroviral, TAMs $=$ thymidine analogue mutations, HAART $=$ highly active antiretroviral therapy, NRTI $=$ nucleoside analogue reverse transcriptase inhibitors, NNRTI = non-nucleoside analogue reverse transcriptase inhibitors, PI = protease inhibitors $\mathrm{OR}=$ odds ratio, $\mathrm{CI}=$ confidence interval.

*Odds ratio for the occurrence or not of mutations when patients were exposed to an increasing number of ARVs and therapeutic regimens.

Table 7. Evidence of changes on ARV exposure, and PR and TR mutations from 2002 to 2006

\begin{tabular}{|c|c|c|c|}
\hline & $\mathrm{OR}^{*}$ & 95\% CI & p-value \\
\hline \multicolumn{4}{|l|}{ ARV exposure } \\
\hline On lamivudine & 1.43 & $1.14-1.78$ & 0.0016 \\
\hline On tenofovir & 1.94 & $1.46-2.57$ & 0.0000 \\
\hline Exposure to tymidine analogues & 0.72 & $0.55-0.94$ & 0.0159 \\
\hline \multicolumn{4}{|l|}{ NRTI-related mutations } \\
\hline M184V & 1.25 & $1.04-1.50$ & 0.0200 \\
\hline L210W & 1.28 & $1.04-1.57$ & 0.0172 \\
\hline K43EQ & 1.45 & $1.08-1.95$ & 0.0127 \\
\hline L228H & 1.44 & $1.09-1.91$ & 0.0094 \\
\hline \multicolumn{4}{|l|}{ NNRTI-related mutations } \\
\hline V108I & 1.44 & $1.03-1.99$ & 0.0313 \\
\hline M230L & 2.40 & $1.11-5.19$ & 0.0256 \\
\hline \multicolumn{4}{|l|}{ PI-related mutations } \\
\hline M46IL & 1.33 & $1.09-1.63$ & 0.0055 \\
\hline I47AV & 2.01 & $1.19-3.40$ & 0.0095 \\
\hline Q58E & 1.59 & $1.08-2.34$ & 0.0183 \\
\hline I54ML & 1.61 & $1.03-2.53$ & 0.0376 \\
\hline T74P & 2.18 & $1.16-4.09$ & 0.0155 \\
\hline
\end{tabular}

$\mathrm{ARV}=$ antiretroviral, NRTI $=$ nucleoside analogue reverse transcriptase inhibitors, NNRTI = non-nucleoside analogue reverse transcriptase inhibitors, PI = protease inhibitors.

$\mathrm{OR}=$ odds ratio, $\mathrm{CI}=$ confidence interval.

*Odds ratio for the occurrence or not of mutations when patients were evaluated from 2002 to 2006. This represents an increase of mutations and ARV exposure. 
Figure 7: Evolution of prevalence of mutations over the years - The graphic represents the frequency of patients with wild-type virus, and with each class mutation pattern. These frequencies were stratified in the genotype samples from 2002, 2003, 2004, 2005, and 2006.

NRTI $=$ nucleoside analogue reverse transcriptase inhibitors, NNRTI $=$ non nucleoside analogue reverse transcriptase inhibitors, PI = protease inhibitor.

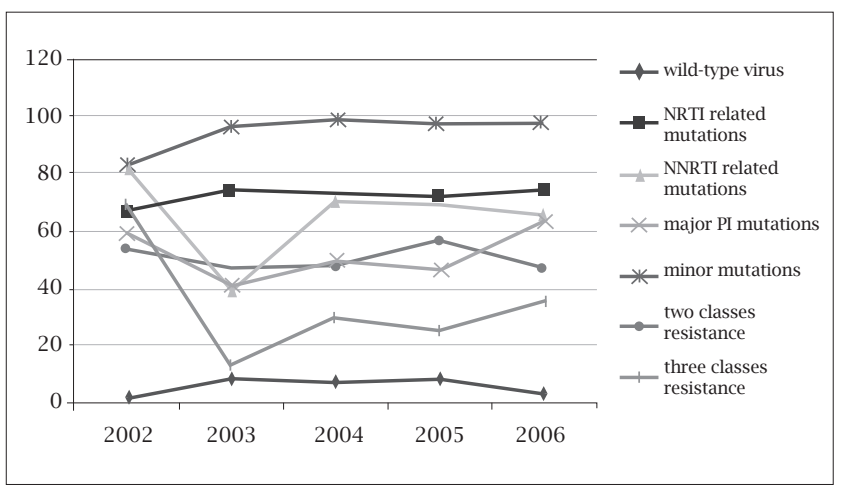

Figure 8: Evolution of NRTI-related mutations over the years The graphic represents the frequency of patients with NRTIrelated mutations. These frequencies were stratified in the genotype samples from 2002, 2003, 2004, 2005, and 2006. All mutations had the same prevalence pattern over the years except the Accessory mutations and the M184V, which have increased from 2002 to 2006. * $(\mathrm{OR} 1.25,95 \% \mathrm{CI}=1.04-1.50$, $\mathrm{p}=0.02), * *(\mathrm{OR} 1.23,95 \% \mathrm{CI}=1.02-1.47, \mathrm{p}=0.0277)$.

TAMs $=$ thymidine analogue mutations, NRTI $=$ nucleoside analogue reverse transcriptase inhibitors, $\mathrm{OR}=$ odds ratio, $\mathrm{CI}=$ confidence interval.

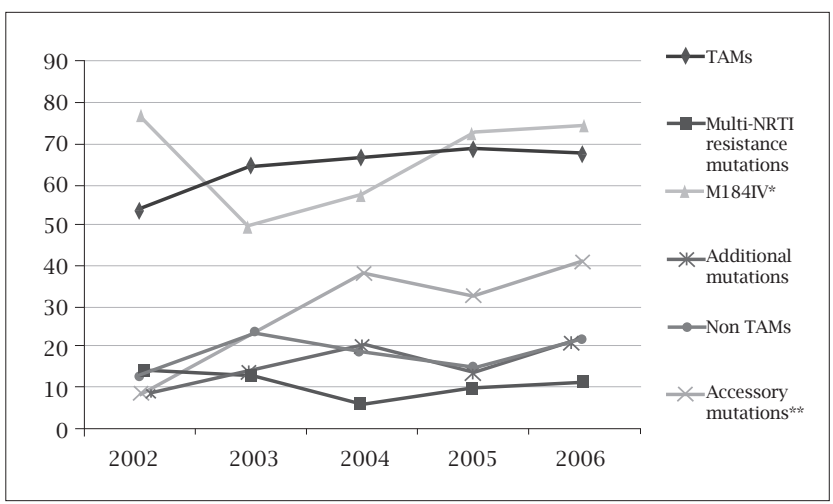

Table 8. Prevalence of mutations according to gender

\begin{tabular}{|lccccccc|}
\hline \multirow{2}{*}{ Mutation } & \multicolumn{2}{c}{ Male sex $(\mathbf{n}=\mathbf{3 0 8})$} & \multicolumn{2}{c}{ Female sex (n=159) } & OR & 95\% IC & p-value \\
& Number $(\mathbf{n})$ & Frequency (\%) & Number (n) & Frequency (\%) & & & \\
\hline M41L & 138 & 44.8 & 46 & 28.9 & 1.99 & $1.32-3.02$ & 0.0009 \\
\hline D67N & 135 & 43.8 & 45 & 28.3 & 1.98 & $1.30-3.00$ & 0.0011 \\
\hline L210W & 88 & 28.6 & 22 & 13.8 & 2.49 & $1.41-4.20$ & 0.0004 \\
\hline T215Y & 118 & 38.3 & 41 & 25.8 & 1.79 & $1.17-2.74$ & 0.0069 \\
\hline > 3 TAMs & 160 & 51.9 & 50 & 31.4 & 1.26 & $1.13-1.40$ & 0.0000 \\
\hline V118I & 76 & 24.7 & 25 & 15.7 & 1.76 & $1.06-2.90$ & 0.0261 \\
\hline M46I & 72 & 23.4 & 16 & 18.2 & 2.73 & $1.51-4.91$ & 0.0005 \\
\hline V82A & 64 & 20.8 & 19 & 11.9 & 1.93 & $1.11-3.37$ & 0.0181 \\
\hline L90M & 93 & 30.2 & 31 & 19.5 & 1.79 & $1.12-2.84$ & 0.0132 \\
\hline I54V & 66 & 21.4 & 16 & 10.1 & 2.4 & $1.35-4.40$ & 0.002 \\
\hline L24I & 17 & 5.5 & 2 & 1.3 & 4.59 & $1.04-20.29$ & 0.0273 \\
\hline
\end{tabular}

TAMs $=$ thymidine analogue mutations, $\mathrm{OR}=$ odds ratio, $\mathrm{CI}=$ confidence interval

\section{DISCUSSION}

This study aimed to estimate HIV drug resistance in patients receiving ART in Paraná, Brazil, from 2002 to 2006. This first estimate of the prevalence of mutations in our region shows a high frequency of resistance, similar to other Brazilian sites but higher for some patterns of mutations.

Almost all patients were exposed to thymidine NRTIs and lamivudine. Double therapy was the initial regimen in more than one third of patients. These features explain the high number of NRTI related mutations.
About half of patients were exposed to NNRTIs and most of them presented NNRTI related mutations. The PI used by most patients was nelfinavir followed by unboosted indinavir, representing the pattern of drug usage in the 90's, when most of these patients started therapy.

The increasing exposure to tenofovir was significant and reflects the availability of this drug after 2002 in clinical trials and in 2004 delivered by the PN-DST/AIDS.

About 15\% of patients were exposed to boosted and unboosted atazanavir and 30\% to boosted lopinavir, the most used PI nowadays, also reflecting the time of inclusion of 
these drugs in the PN-DST/AIDS during the study period. Less than $1 \%$ of patients were exposed to darunavir, PI available since 2004 in clinical trials.

The most frequent mutations in RT were associated to lamivudine and NNRTIs exposure, which confirms the low genetic barrier of these drugs. ${ }^{42}$

Due to high prevalence of exposure to thymidine analogues and the presence of TAMs, K65R is expected to occur in a very low prevalence, as in the presence of multiple TAMs K65R is rarely selected on the same human immunodeficiency virus type 1 genome in vivo. ${ }^{43}$

In this study, the prevalence of mutations was significantly higher in the group of patients exposed to more drugs and more regimens. This was the case for TAMs, NRTI accessory mutations, NNRTI related mutations and major PI mutations. Initial double therapy was also significantly associated to more TAMs.

Patients starting HAART with a regimen including NNRTI presented less TAMs, probably because, besides avoiding double therapy, the tolerability of this regimens promoted better adherence. The same was not seen in the group starting HAART with a regimen including unboosted PIs, frequently a less tolerable regimen. Additionally, patients starting with unboosted PIs were exposed to higher number of drugs (6.99 versus 4.75 ) and regimens (3.75 versus 2.29 ) than patients starting with NNRTIs.

The low prevalence (less than 5\%) of mutations associated with classes not previously used may represent primary resistance, acquired resistance or a false positive result. For patients exposed only to NNRTI and NRTI presenting major PI mutations, primary resistance is a possibility, since PI where first available to treatment for this group of patients tested in the early 2000's.

The association between exposure to thymidine analogues and higher number of TAMs was not neither significant in univariates or multivariate analyses as almost all patients were exposed to these drugs, but the longer time of exposure (specially to $\mathrm{d} 4 \mathrm{~T}$ ) was significantly associated to more TAMs. Tenofovir and ddI exposure were significantly associated to higher number of TAMs not as a causal relationship, but because patients with exposure to more regimens had more TAMs and consequently were exposed to tenofovir and ddI since 2004.

Almost $5 \%$ of patients had no mutations in RT and PR, similarly to other Brazilian reports, where the prevalence of wild-type virus was less than $10 \%$ of samples. ${ }^{21,23,25,26}$ Only one national study showed even higher prevalence of wildtype virus $(15.3 \%))^{20}$

The most prevalent mutation occurred at codon 184 (68.31\%), as reported in São Paulo (64\%), ${ }^{24}$ Rio de Janeiro $(67 \%),{ }^{23}$ and Northeast Brazil (66\%). ${ }^{25}$ In Santos, from 2006, this mutation was even more prevalent $(88 \%) .{ }^{27}$ In Paraná, when samples from 2006 were analysed, the prevalence of
M184V was of $75 \%$, consistent with the significant increase of lamivudine exposure.

The frequency of mutations was high for all classes of antiretrovirals, which was expected for patients who had already been on different antiretroviral regimens. Predominantly, primary mutations were associated with NRTIs and NNRTIs. The high prevalence of TAMs (67.24\%) was similar to that reported in São Paulo (73\%). ${ }^{24}$

The K65R mutation was not reported in most national studies and has occurred in less than $1 \%$ of the patients in this study. At Brazilian Northeast region this mutation was seen in $3.4 \%$ of patients and, specifically in the state of Ceará, in $5.9 \%$ of cases. ${ }^{23,26}$

The overall prevalence of NNRTI mutations (67.7\%) was higher than in other Brazilian series, probably because recently described NNRTI mutations (codons 101, 106, 179) were included in the analysis. Most of other Brazilian studies reported NNRTI prevalence of mutations of 30 to $55.4 \% .{ }^{21,23,25,26}$ In Santos, the overall NNRTI prevalence was not explicit, but $\mathrm{K} 103 \mathrm{~N}$ occurred in $52 \%$ of patients, whereas in these data from Paraná it was $43.4 \% .{ }^{27}$ At Brazilian Northeast region, the specific mutations were even higher, with $62 \%$ substitutions in codon $103,38.7 \%$ in codon 190 and 181 in codon $29.2 \% .{ }^{25}$ At Rio de Janeiro, K103N was seen in $27.7 \%$, but the the frequency of other mutations was similar to what was observed in Paraná: G190S/A in 22.12\%, and $\mathrm{Y} 181 \mathrm{C} / \mathrm{I}$ in $17.4 \% .^{23}$

The PI related mutations were comparable to many other series. Mutation at codon 90 was the most frequent, followed by codons 46 and 82 , prevalences similar to 25.5 , 23.7 and $21.1 \%$, respectively reported by Cavalcanti et al. (2005). ${ }^{23}$ In the other Brazilian studies, L90M was also the most frequent, present in 26 to $37 \%$ of the cases. . $^{20,21,23,24,44}$

Compared with international data, these patients present lower prevalence of wild-type virus, probably because in other sites - where genotype was available earlier in the setting of virologic failure - more wild-type virus can be demonstrated. Other reason may be the lower exposure to less effective regimens, including less than two active agents. The prevalence of wild-type virus ranged from 14 to $22 \%$ in many trials. ${ }^{14,16,17,45,46}$

The pattern of PI and NRTI resistance mutations in Paraná was similar to some international series. PI resistance mutations occurred in 41 to $53 \%$ and NRTI related mutations occurred in 71 to $80 \%$ of samples from Spain, France, Italy and USA. ${ }^{14,17,45-48}$

Data from other countries showed lower prevalence (25 to $52 \%$ ) of NNRTI mutations than this study. ${ }^{14,15,17,45-48}$

The most prevalent mutations worldwide were at codons 184 and 103 of TR, and 90 of PR, but they were less frequently than in this sample. M184V/I, K103N and L90M occurred respectively in 49.27 and $31 \%$ of patients in Spain and in 58.31 e $31 \%$ of patients in France. ${ }^{44,48}$ Napravnik 
et al. (2007) reported 79, 58 and 59\% of M184V/I, K103N and $\mathrm{L} 90 \mathrm{M}$ mutations respectively, but the analysis included only patients with three-class resistance, which explains this high prevalence. ${ }^{19}$ Rhee et al. (2004) reported K65R in 1.9\% of patients and Costagliola et al. (2007) reported it in 5\% of cases. ${ }^{16,49}$

The prevalence of mutations conferring resistance to the three ARV classes was similar and even higher than other national and international studies in which it has been shown to be about 17 to $21 \% .^{25,46-48}$

No decrease in the prevalence of mutations has been observed in the sample from Paraná over the years, but some European studies did show an overall decrease in prevalence of TR and PR mutations, reflecting a better response to HAART. ${ }^{40-52}$

Differences in gender related prevalence are not widely described, but Di Giambenedetto et al. (2007), according to data from some mutations in Paraná, considered male sex an independent predictor of drug resistance..$^{50}$

In terms of NNRTIs as future treatment options for this group of patients, it has been found that mutations on RT codons 181 and 190 occurred in more than $20 \%$ of patients, which could compromise etravirine efficacy if used in a suboptimal regimen. The new PI darunavir is an important future option to this group, as mutations limiting DRV/r response occurred in less than $10 \%$, and PR mutations $50 \mathrm{~V}$, $54 \mathrm{ML}$ and $76 \mathrm{~V}$ occurred in less than $5 \%$ of patients.

\section{CONCLUSION}

In conclusion, we showed a high frequency of resistance mutations to antiretroviral drugs in patients with virologic failure on ART in Paraná, from 2002 to 2006. This was more important to the NNRTI class compared to other studies. No reduction in the prevalence of mutations over the years was seen, as described in other countries. Prevalence of mutations and multidrug-resistant viruses needs to be monitored in the future in relation to the evolution of HAART.

Hopefully, the diminishing practice of sequential monotherapy and the availability of more effective and better tolerated combination regimens, since 2006, will improve suppression of viremia, resulting in prevention of acquired resistance.

\section{ACKNOWLEDGEMENTS}

The authors would like to thank Dra. Silvia Maria Gomes de Rossi, for giving us access to the genotypes at Centro Regional de Especialidades Barão, Curitiba. Our gratitude also is extended to Dra. Lilian Amaral Inocêncio, from the Programa Nacional de DST/AIDS for helping with the approval process of the tests studied. Assistance of Patrícia Monteiro, Roberta Terfiglio, Gaston Picchio and Eric Lefebvre, helping with the availability of tests from VIRCO is appreciated.

\section{REFERENCES}

1. Okie S. Fighting HIV - lessons from Brazil. N Engl J Med 2006; 11; 354:1977-81.

2. Brazilian Program for STD/AIDS. Response + Magazine 2008: Experiences of the Brazilian AIDS Programme. Brasília, Brazil: Ministry of Health, 2008:80. [cited 2009 february 12] Available from: http://aids.gov.br/data/documents/storedDocuments

3. Vella S, Palmisano L. The Global Status of Resistance to Antiretroviral Drugs. Clin Infect Dis 2005; 41(Suppl 4):S239-46.

4. Coffin JM. HIV population dynamics in vivo: implications for genetic variation, pathogenesis and therapy. Science 1995; 267:483-9.

5. Hu DJ, Dondero TJ, Rayfield MA et al. The emerging genetic diversity of HIV. The importance of global surveillance for diagnostics, research, and prevention. JAMA 1996; 275:210-6.

6. Iversen AKN, Shafer RW, Wehrly K et al. Multidrugresistant human immunodeficiency virus type I strains resulting from combination antiretroviral therapy. J Virol 1996; 70:1086-90.

7. Ledergerber B, Egger M, Opravil M et al. Clinical progression and virological failure on highly active antiretroviral therapy in HIV-1 patients: a prospective cohort study. Lancet 1999; 353:863-8.

8. Shafer RW, Winters MA, Palmer S, Merigan TC. Multiple concurrent reverse transcriptase and protease mutations multidrug resistance of HIV-1 isolates from heavily treated patients. Ann Intern Med 1998; 128:906-11.

9. Larder BA, Darby G, Richman D. HIV with reduced sensitivity to zidovudine (AZT) isolated during prolonged therapy. Science 1989; 243:1731-4.

10. Larder BA, Kemp SD. Multiple mutations in HIV-1 reverse transcriptase confer high-level resistance to Zidovudine (AZT). Science 1989; 246:1155-8.

11. Shafer RW, Rhee SY, Zioni R, Liu T, Kiuchi M. Stanford University HIV drug resistance database. [cited 2008 october 2] Available from: http://hivdb.stanford.edu/pages/asi/releaseNotes

12. Johnson VA, Brun-Vézinet F, Clotet B et al. Update of the drug resistance mutations in HIV-1: December 2008. Top HIV Med 2008; 16:138-45.

13. Hirsch MS, Günthard HF, Schapiro JM et al. Antiretroviral drug resistance testing in adult HIV-1 infection: 2008 recommendations of an International AIDS Society-USA panel. Clin Infect Dis 2008; 47:266-85.

14. Tamalet C, Fantini J, Tourres C, Yahi N. Resistance of HIV-1 to multiple antiretroviral drugs in France: a 6-year survey (19972002) based on an analysis of over 7000 genotypes. AIDS 2003; 17:2383-8.

15. Scott P, Arnold E, Evans B et al. Surveillance of HIV antiretroviral drug resistance in treated individuals in England: 1998-2000. J Antimicrob Chemother 2004; 53:469-73.

16. Rhee SY, Liu T, Ravela J, Gonzales MJ, Shafer RW. Distribution of Human Immunodeficiency Virus Type 1 Protease and Reverse Transcriptase Mutation Patterns in 4,183 Persons Undergoing Genotypic Resistance Testing. Antimicrob Agents Chemother 2004; 48:3122-6.

17. Richman DD, Morton SC, Wrin T et al. The prevalence of antiretroviral drug resistance in the United States. AIDS 2004; 18:1393401.

18. Rhee SY, Fessel WJ, Zolopa AR et al. HIV-1 Protease and reversetranscriptase mutations: correlations with antiretroviral therapy in subtype B isolates and implications for drug-resistance surveillance. J Infect Dis 2005; 192:456-65. 
19. Napravnik S, Keys JR, Quinlivan EB, Wohl DA, Mikeal OV, Eron JJ Jr. Triple-class antiretroviral drug resistance: risk and predictors among HIV-1-infected patients. AIDS 2007; 21:82534 .

20. Tanuri A, Caridea E, Dantas MC et al. Prevalence of mutations related to HIV-1 antiretroviral resistance in Brazilian patients failing HAART. J Clin Virol 2002; 25:39-46.

21. Bahia F, Pedroso C, Netto EM, Figueiredo R, Pinto Neto L, Brites C. Evaluation of the Genotypic Pattern of HIV-1 Resistance in AIDS Patients Failing Antiretroviral Therapy. Braz Journal Infec Dis 2004; 8:281-9.

22. Cerqueira DM, Amorim RM, Silva RR, Camara GN, Brígido MM, Martins CR. Antiretroviral resistance and genetic diversity of human immunodeficiency virus type 1 isolates from the Federal District, Central Brazil. Mem Inst Oswaldo Cruz 2004; 99:877-82.

23. Couto-Fernandez JC, Silva-de-Jesus C, Veloso VG et al. Human immunodeficiency virus type 1 (HIV-1) genotyping in Rio de Janeiro, Brazil: assessing subtype and drug-resistance associated mutations in HIV-1 infected individuals failing highly active antiretroviral therapy. Mem Inst Oswaldo Cruz 2005; 100:73-8.

24. Rodrigues R, Vazquez CMP, Colares JK et al. Antiretroviral resistance mutations in human immunodeficiency virus type 1 infected patients enrolled in genotype testing at the Central Public Health Laboratory, São Paulo, Brazil: preliminary results. Mem Inst Oswaldo Cruz 2005; 100:97-102.

25. Cavalcanti AM, Lacerda HR, Brito AM, Pereira S, Medeiros D, Oliveira S. Antiretroviral resistance in individuals presenting therapeutic failure and subtypes of the human immunodeficiency virus type 1 in the Northeast Region of Brazil. Mem Inst Oswaldo Cruz 2007; 102:785-92.

26. Medeiros MS, Arruda EA, Guerrant RL et al. Genotype testing and antiretroviral resistance profiles from HIV-1 patients experiencing therapeutic failure in northeast Brazil. Braz J Infect Dis 2007; 11:390-4.

27. de Sa-Filho DJ, Soares MS, Candido V et al. HIV type 1 pool gene diversity and antiretroviral drug resistance mutations in Santos, Brazil. AIDS Res Hum Retroviruses 2008; 24:347-53.

28. Shafer RW, Schapiro JM. HIV-1 drug resistance mutations: an updated framework for the second decade of HAART. AIDS Rev 2008; 10:67-84.

29. Hirsch MS, Brun-Vézinet F, DAquila RT et al. Antiretroviral drug resistance testing in adult HIV-1 infection: recommendations of an International AIDS Society-USA Panel. JAMA 2000; 283:2417-26.

30. DAquila RT, Schapiro JM, Brun-Vézinet F et al. Update on Drug Resistance Mutations in HIV-1. International AIDS Society - USA Resistance Mutations Project Panel. Top HIV Med 2001; 9:31-3.

31. DAquila RT, Schapiro JM, Brun-Vézinet F et al. Update on Drug Resistance Mutations in HIV-1. International AIDS Society - USA Resistance Mutations Project Panel. Top HIV Med 2001; 9:21-3.

32. DAquila RT, Schapiro JM, Brun-Vézinet F et al. Drug resistance mutations in HIV-1. International AIDS Society - USA Drug Resistance Mutations Group. Top HIV Med 2002; 10:11-5.

33. DAquila RT, Schapiro JM, Brun-Vézinet F et al. Drug resistance mutations in HIV-1. Top HIV Med 2002; 10:21-5.

34. DAquila RT, Schapiro JM, Brun-Vézinet F et al. Drug resistance mutations in HIV-1. Top HIV Med 2003; 11:92-6.

35. Johnson VA, Brun-Vézinet F, Clotet B et al. International AIDS Society-USA Drug Resistance Mutations Group. Drug resistance mutations in HIV-1. Top HIV Med 2003; 11:215-21.
36. Johnson VA, Brun-Vézinet F, Clotet B et al. Update of the drug resistance mutations in HIV-1: 2004. Top HIV Med 2004; 12:119-24

37. Johnson VA, Brun-Vézinet F, Clotet B et al. Update of the drug resistance mutations in HIV-1: 2005. Top HIV Med 2005; 13:51-7.

38. Johnson VA, Brun-Vezinet F, Clotet B et al. Update of the drug resistance mutations in HIV-1: Fall 2005. Top HIV Med 2005; 13:125-33.

39. Johnson VA, Brun-Vézinet F, Clotet B et al. Update of the drug resistance mutations in HIV-1: Fall 2006. Top HIV Med 2006; 14:125-30

40. Johnson VA, Brun-Vézinet F, Clotet B et al. Update of the drug resistance mutations in HIV-1: 2007. Top HIV Med 2007; 15:119-25.

41. Johnson VA, Brun-Vezinet F, Clotet B et al. Update of the Drug Resistance Mutations in HIV-1: Spring 2008. Top HIV Med 2008; 16:62-8.

42. Bangsberg DR, Acosta EP, Gupta R et al. Adherence-resistance relationships for protease and non-nucleoside reverse transcriptase inhibitors explained by virological fitness. AIDS 2006; 20:223-31.

43. Sucupira MC, Souza IE, Costa LJ, Scheinberg MA, Diaz RS. Antiretroviral treatment failure and HIV-1 genotypic resistance in São Paulo, Brazil. Antivir Ther 2001; 6:263-4.

44. Parikh UM, Barnas DC, Faruki H, Mellors JW. Antagonism between the HIV-1 reverse-transcriptase mutation K65R and thymidine-analogue mutations at the genomic level. J Infect Dis 2006; 194:651-60.

45. Gallego O, Ruíz L, Vallejo A, Clotet B, Leal M, Soriano V. Rate of virological treatment failure and frequencies of drug resistance genotypes among human immunodeficiency virus-positive subjects on antiretroviral therapy in Spain. J Clin Microbiol 2002; 40:3865-6.

46. Zazzi M, Corsi P, Gonnelli A et al. Evolution of the prevalence of HIV drug resistance patterns over 9 years of HAART and its relation with changes in the failing treatment regimens: an analysis of a large Italian database. XV International HIV Drug Resistance Workshop; Sitges, Spain. Antivir Ther 2006:S137.

47. Violin M, Galli A, Corvasce S et al. Study of antiretroviral resistance in treated patients with virological failure (START study): an Italian survey over the period 2003-2005. XV International HIV Drug Resistance Workshop; Sitges, Spain. Antivir Ther 2006:S132.

48. Pillay D, Green H, Matthias R et al. Estimating HIV-1 drug resistance in antiretroviral-treated individuals in the United Kingdom. J Infect Dis 2005; 192:967-73.

49. Costagliola D, Descamps D, Assoumou L et al. Agence Nationale de Recherches sur le SIDA et les Hepatites Virales (ANRS) AC11 Resistance Study Group. Prevalence of HIV-1 drug resistance in treated patients: a French nationwide study. J Acquir Immune Defic Syndr 2007; 46:12-8.

50. Di Giambenedetto S, Bracciale L, Colafigli M et al. Declining prevalence of HIV-1 drug resistance in treatment-failing patients: a clinical cohort study. Antivir Ther 2007; 12:835-9. Erratum in: Antivir Ther 2007; 12:1145.

51. Vercauteren J, Deforche K, Theys K et al. The incidence of multidrug and full class resistance in HIV-1 infected patients is decreasing over time (2001-2006) in Portugal. Retrovirology 2008; 5:1-8.

52. Lohse N, Obel N, Kronborg G et al. Declining prevalence of HIV-infected individuals at risk of transmitting drug-resistant HIV in Denmark during 1997-2004. Antivir Ther 2006; 11:591-600. 